01,07

\title{
Влияние импульсного лазерного ИК-излучения на динамику и морфологию деформационных полос в алюминий-магниевом сплаве
}

\author{
(C) А.А. Шибков, А.Е. Золотов, М.Ф. Гасанов, М.А. Желтов, К.А. Проскуряков \\ Тамбовский государственный университет им. Г.Р. Державина, \\ Тамбов, Россия \\ E-mail: shibkov@tsu.tmb.ru
}

(Поступила в Редакцию 3 марта 2018 г.)

\begin{abstract}
Методом высокоскоростной видеосъемки исследовали динамику и морфологию деформационных полос в условиях одновременного действия механической нагрузки и импульсного лазерного ИК-излучения на поверхность алюминий-магниевого сплава АМг6. Определены условия, при которых пробивание лазерным импульсом сквозного отверстия диаметром на порядок меньшим толщины плоского образца вызывает развитие сложной пространственно-временно́й структуры деформационных полос и макроскопического скачка на диаграмме растяжения. Выявлены морфологические переходы, связанные с изменением типа и формы полос и их пространственно статистического распределения при изменении плотности энергии лазерного импульса. Обсуждается возможный механизм этого явления.
\end{abstract}

Результаты работы получены с использованием оборудования ЦКП ТГУ им. Г.Р. Державина.

Работа выполнена при финансовой поддержке Российского научного фонда (проект № 17-79-10404).

DOI: $10.21883 /$ FTT.2018.09.46376.063

\section{1. Введение}

Высокотехнологичные свариваемые авиационные алюминий-магниевые сплавы с содержанием магния 3-6\% являются типичными сплавами, демонстрирующими макроскопическую прерывистую деформацию в технологически значимой области температур, скоростей деформации и напряжений. Прерывистая деформация проявляется в виде повторяющихся скачков напряжения при деформировании с заданной скоростью $\dot{\varepsilon}_{0}=$ const (эффект Портевена-Ле Шателье $[1,2]$ ) или в виде повторяющихся ступеней на диаграммах растяжения с заданной скоростью нагружения $\dot{\sigma}_{0}=$ const (эффект Савара-Массона $[1,3])$, а также в условиях ползучести $\sigma_{0}=$ const (,лестничная“ или прерывистая ползучесть [4]). Прерывистая деформация сопровождается образованием и распространением полос макролокализованной деформации, которые ухудшают качество поверхности промышленных изделий и могут вызвать внезапное разрушение. Механизмы образования деформационных полос и их влияние на механические свойства сплавов до сих пор являются дискуссионными вопросами [2,5]. Изучение влияния внешних воздействий на образование деформационных полос и прерывистую деформацию является сравнительно новым направлением исследования механизмов макроскопических пластических неустойчивостей. В работе [6] обнаружено и исследовано явление подавления деформационных полос и упрочнение сплавов системы $\mathrm{Al}-\mathrm{Mg}$ электрическим током, а в работах $[7,8]$ - влияние локального воздействия агрессивной среды на развитие пластических неустой- чивостей алюминий-магниевого сплава АМг6. В настоящей работе исследуется влияние локального воздействия ИК-лазера на полосообразование и прерывистую деформацию сплава АМг6. Исследования в данном направлении позволят определить условия формирования деформационных полос и их влияние на прочность алюминиевого сплава в процессе лазерной сварки под напряжением. Цель данной работы - исследование динамики зарождения и распространения деформационных полос в результате локального импульсного воздействия волоконного ИК-лазера на поверхность деформируемого сплава АМг6.

\section{2. Методика}

Поликристаллические образцы сплава АМг6 (Al, 6.03 wt. $\% \mathrm{Mg}, 0.5$ wt.\% Mn) в форме двухсторонних лопаток с размерами рабочей части $6 \times 3 \times 0.5 \mathrm{~mm}$ вырезали из листового проката после холодной прокатки (степень обжатия 0.3). Образцы предварительно отжигали в течение $\mathrm{h}$ при температуре $450^{\circ} \mathrm{C}$ и закаливали на воздухе. После термообработки размер зерна составил $10 \mu \mathrm{m}$. Растяжение образцов проводили с постоянной скоростью возрастания напряжения $\dot{\sigma}_{0}=$ const при комнатной температуре в мягкой деформационной машине, описанной в [9]. В этих условиях в отсутствие внешних воздействий сплав АМг6 демонстрирует ступенчатую диаграмму растяжения. Деформацию образца измеряли с помощью триангуляционного датчика положения фирмы Riftec с точностью $1.5 \mu \mathrm{m}$ в полосе частот $0-2 \mathrm{kHz}$, а силовой отклик механической системы 


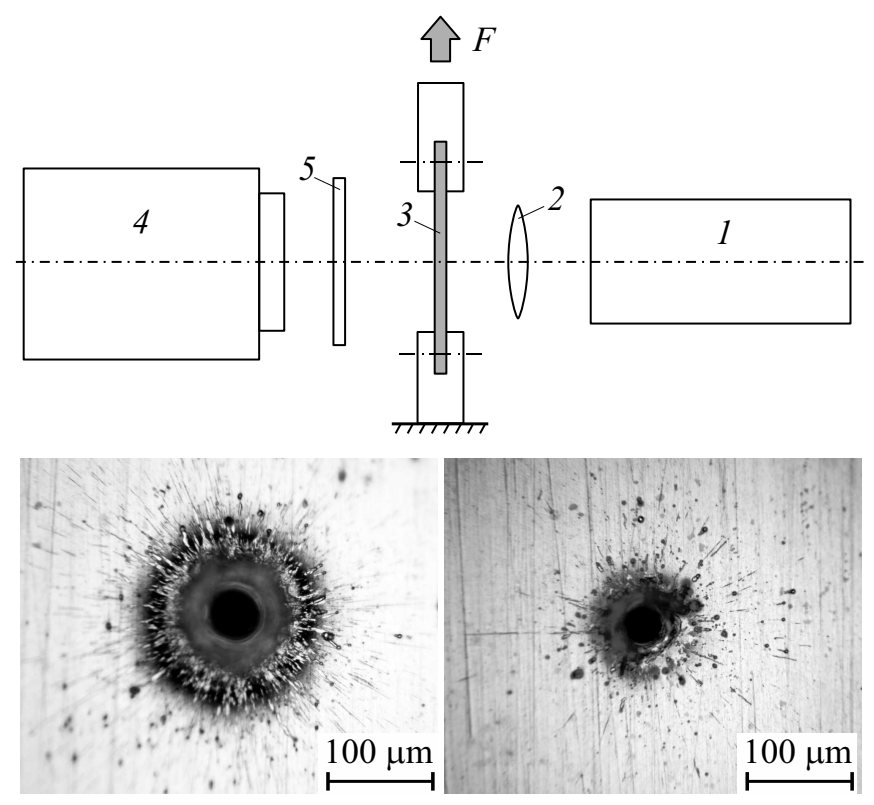

Рис. 1. Схема эксперимента: $1-$ импульсный ИК-лазер, 2 - собирающая линза, 3 - плоский металлический образец, 4 - высокоскоростная видеокамера, 5 - защитное стекло. На вставках фотографии кратера при мощности излучения $P_{1}=50 \mathrm{~W}$ (слева) и $P_{2}=25 \mathrm{~W}$ (справа).

машина-образец измеряли с помощью датчика усилия Zemic H3-C3-100 kg-3 В с чувствительностью $1.5 \mu \mathrm{V} / \mathrm{N}$. Скорость регистрации данных этих датчиков устанавливали равной $2 \mathrm{kHz}$. Измерения датчиков синхронизировали с высокоскоростной цифровой видеокамерой VS-FAST/G6 (НПК „Видеоскан“). Скорость видеосьемки поверхности составляла $500 \mathrm{frames} / \mathrm{s}$. Обработка видеофильма состояла в вычитании с помощью компьютерной программы последовательных во времени кадров видеофильма [3].

Схема эксперимента для исследования лазерного излучения на прерывистую деформацию и динамику деформационных полос показана на рис. 1. Источником излучения служил волоконный иттербиевый импульсный ИК-лазер YLP-1-100-50-50-HC-RG с длиной волны $\lambda=1.06 \mu \mathrm{m}$ со средней мощностью до $50 \mathrm{~W}$. Излучение лазера (1) собиралось линзой (2) с фокусным расстоянием $80 \mathrm{~mm}$ на поверхность деформируемого образца (3) в пятно с гауссовым радиусом $r_{0} \approx 70 \mu \mathrm{m}$. Видеосъемку противоположной стороны поверхности образца вели с помощью высокоскоростной цифровой видеокамеры (4) через защитное стекло (5), которое предохраняло матрицу камеры от возможного попадания ИК-излучения. Использовали режим „свободной“ генерации в течение $20 \mathrm{~ms}$ импульсов излучения длительностью $120 \mathrm{~ns}$ с частотой модуляции $70 \mathrm{kHz}$ (время генерации задавалось прямоугольным импульсом напряжения длительностью $20 \mathrm{~ms}$ в режиме внешнего управления лазера). Данный режим в дальнейшем будет называть режимом одиночного „импульса“ длительностью $t_{p}=20 \mathrm{~ms}$.

Такой режим воздействия является оптимальным для сквозного локального проплавления алюминиевого листа толщиной $0.5 \mathrm{~mm}$ и поэтому близок к условиям лазерной сварки. Действительно, согласно [10], величина плотности потока $F_{c r}$, при которой происходит переход из области, где теплопроводность является определяющим механизмом, в область, где теплопроводностью можно пренебречь по сравнению с механизмом испарения определяется соотношением: $F_{c r} \approx 2 L \rho\left(a / t_{p}\right)^{1 / 2}$, где $L-$ скрытая теплота испарения, $\rho-$ плотность сплава, $a-$ коэффициент температуропроводности. При $F>F_{c r}$ контролирующим механизмом является испарение, а при $F<F_{c r}$ - теплопроводность и плавление. Для сплава АМг6 [11]: $L=1.07 \cdot 10^{4} \mathrm{~kJ} / \mathrm{kg}, a=0.43 \cdot 10^{-4} \mathrm{~m}^{2} / \mathrm{s}$, $\rho=2.64 \cdot 10^{3} \mathrm{~kg} / \mathrm{m}^{3}$ и при $t_{p}=20 \mathrm{~ms}$ получим из формулы $F_{c r}=2.6 \cdot 10^{5} \mathrm{~W} / \mathrm{cm}^{2}$. Реальная плотность потока $F=P / S_{0} \approx 1.3 \cdot 10^{5} \mathrm{~W} / \mathrm{cm}^{2}$ при средней мощности излучения $P=20 \mathrm{~W}$ и $S_{0}=\pi r_{0}^{2}=1.54 \cdot 10^{-4} \mathrm{~cm}^{2}$, поэтому $F<F_{c r}$ и в нашем случае доминирующим механизмом поглощения энергии лазерного импульса является теплопроводность и плавление.

Оценим теперь характерные времена теплового воздействия лазерного излучения: время $t_{m}$, прошедшее от начала теплового импульса до момента, в который начинается плавление поверхности металла и тепловую постоянную времени $\tau_{m}$, т.е. время, за которое температура обратной стороны пластины толщиной $l$ достигает величины порядка температуры на передней поверхности, где поглощается энергия. Согласно [10],

$$
\begin{gathered}
t_{m}=\frac{\pi}{4 a}\left(\frac{\lambda T_{m}}{F}\right)^{2}, \\
\tau_{m}=l^{2} / 4 a,
\end{gathered}
$$

где $\lambda$ - теплопроводность кристаллического алюминия, $T_{m}$ - температура плавления. Принимая в нашем случае $l=0.5 \mathrm{~mm}, \lambda=225.25 \mathrm{~W} / \mathrm{mK}, T_{m}=933.2 \mathrm{~K}$, получим $t_{m} \approx 0.5 \mathrm{~ms}$ и $\tau_{m} \approx 1.5 \mathrm{~ms}$. Приведенные оценки величин $t_{m}$ и $\tau_{m}$ оказываются на несколько порядков меньше характерных времен развития деформационной неустойчивости на ступенчатых диаграммах растяжения сплава: времени развития ступени $\sim 0.5 \mathrm{~s}$ и продолжительности плато между ступенями $\sim 30-100 \mathrm{~s}$ [3].

Для характеризации зоны упрочнения после воздействия лазерного импульса, вызывающего сквозное проплавление, на противоположной от кратера поверхности плоского образца измеряли микротвердость HV на приборе ПМТ-3М в течение $10 \mathrm{~s}$ с использованием груза массой $10 \mathrm{~g}$.

\section{3. Результаты и обсуждение}

Типичная ступенчатая кривая растяжения с постоянной скоростью возрастания напряжения $\dot{\sigma}_{0}=$ const 

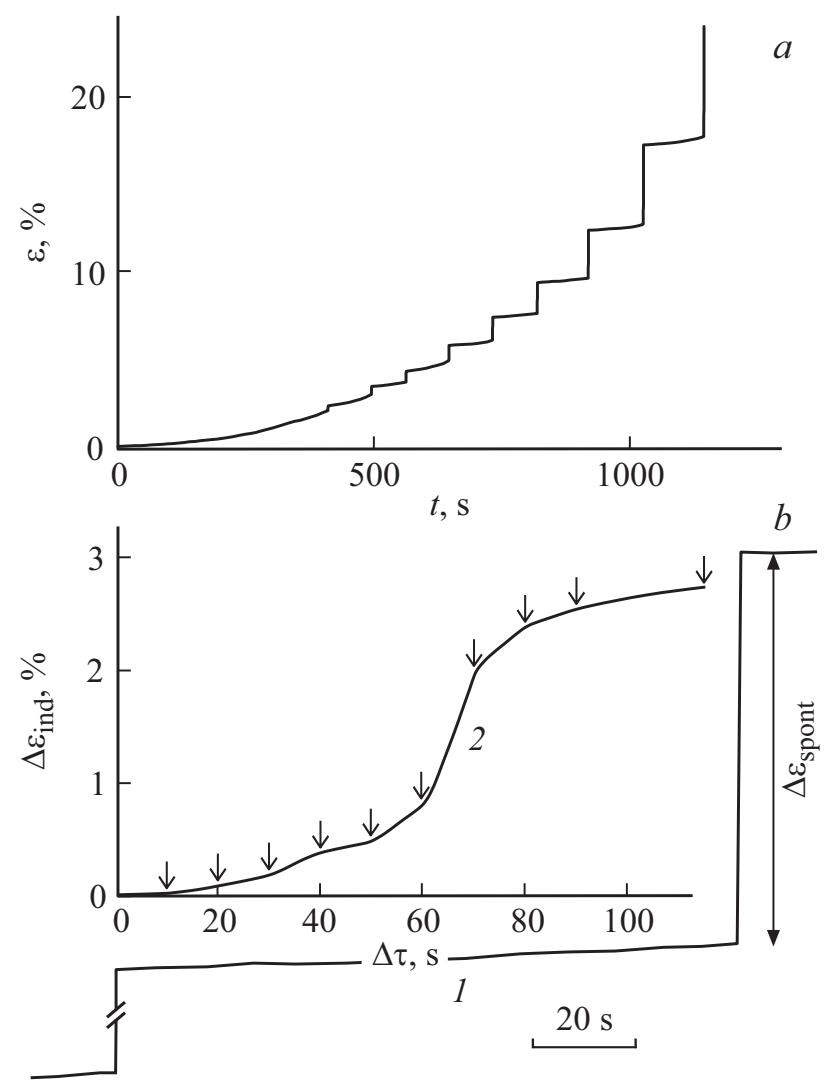

Рис. 2. a) Диаграмма растяжения образца сплава АМг6 в „мягкой“ деформационной машине. b) Фрагмент диаграммы растяжения (1), демонстрирующий плато длительностью около $130 \mathrm{~s}$ между скачками и зависимость амплитуды деформационного скачка $\Delta \varepsilon_{\text {ind }}$, индуцированного лазерным уколом поверхности, от времени $\Delta \tau$ между началом „плато“ и моментом импульсного лазерного воздействия (2). $P_{1}=50 \mathrm{~W}$, $\sigma=270 \mathrm{MPa}, \dot{\sigma}_{0}=0.2 \mathrm{MPa} / \mathrm{s}$. Стрелки - экспериментальные точки, усредненные по пяти образцам.

(эффект Савара-Массона) сплава АМг6 представлена на рис. 2, $a$. При комнатной температуре обычно наблюдается около десятка ступеней на кривой растяжения, а разрушение образца происходит на фронте последнего скачка максимальной амплитуды, до 10\% [12]. С ростом приложенного напряжения растет амплитуда скачков деформации (ступеней на деформационной кривой) и плато между скачками, т. е. величина прироста напряжения $\Delta \sigma$ между скачками. Для алюминий-магниевых сплавов зависимость $\Delta \sigma$ от амплитуды предыдущего скачка $\Delta \varepsilon$ приближенно апроксимируется степенной функцией

$$
\Delta \sigma=A \Delta \varepsilon^{n},
$$

где постоянные $A$ и $n$ зависят от марки сплава, температуры $T$ испытания и скорости нагружения. Для АМг6, деформируемого со скоростью нагружения $\dot{\sigma}_{0}=0.2 \mathrm{MPa} / \mathrm{s}$ при $T=300 \mathrm{~K}, A=45 \mathrm{MPa}, n=0.273$.

Эмпирическая зависимость (3) позволяет непосредственно в ходе нагружения сплава оценивать длитель- ность плато $\Delta t=\Delta \sigma / \dot{\sigma}_{0}$ после скачка амплитудой $\Delta \varepsilon$ и предсказывать момент появления очередного скачка. В работе [7] экспериментально установлено, что последняя треть плато наиболее чувствительна к локальному воздействию на поверхность деформируемого сплава АМг6 агрессивной среды: нанесение капли 30\%-го раствора $\mathrm{HCl}$ на поверхность плоского образца на данном интервале плато (измеренного в отсутствие внешних воздействий) вызывает формирование сложной пространственно-временно́й структуры деформационных полос и развитию деформационной ступени с амплитудой несколько процентов на кривой растяжения.

Деформационный отклик на локальное воздействие импульсного лазерного ИК-излучения демонстрирует, как обнаружено, качественно подобное поведение. Для его количественного исследования выбиралось плато между скачками достаточно большой амплитуды $>2-3 \%$, (обычно между 7-м и 8-м скачком, см. pис. $2, a)$. При скорости нагружения $\dot{\sigma}_{0}=0.2 \mathrm{MPa} / \mathrm{s}$ его длительность составляла $\Delta t=t_{8}-t_{7} \approx 130 \mathrm{~s}$. Затем деформируемые образцы на данном плато подвергались импульсному лазерному „уколу“ в центральную область в разные моменты времени $\Delta \tau=t-t_{7}$ относительно начала плато, измеряли амплитуду скачка $\Delta \varepsilon_{\text {ind }}$, индуцированного лазерным воздействием, и исследовали динамику и морфологию деформационных полос на фронте этого скачка.

На рис. 2, $b$ представлен фрагмент кривой нагружения (кривая 1), показывающий исследуемое плато (между 7-м и 8-м спонтанными скачками), полученное в отсутствие лазерного воздействия, и зависимость амплитуды $\Delta \varepsilon_{\text {ind }}$ скачка, индуцированного лазерным уколом, от времени $\Delta \tau$, отсчитанного от начала плато (кривая 2). Данная зависимость построена при постоянной для всех деформируемых образцов плотности потока лазерного излучения $F_{1}=3.25 \mathrm{~W} / \mathrm{cm}^{2}$, соответствующей сквозному проплавлению плоского образца. Мощность излучения составляла $P_{1}=50 \mathrm{~W}$, а плотность энергии излучения $\Phi_{1}=F_{1} t_{p}=6.5 \mathrm{\kappa J} / \mathrm{cm}^{2}$.

Как видно из рис. $2, b$, деформационный отклик на локальное импульсное воздействие ИК-лазера нелинейно зависит от временно́й фазы воздействия. Если момент времени нанесения лазерного укола приходится на начальный участок плато (до $\Delta \tau \sim 0.15 \Delta t \approx 20 \mathrm{~s}$ ), то такое воздействие (сквозное проплавление) не вызывает заметного скачка пластической деформации на кривой растяжения. С ростом $\Delta \tau$ до $60 \mathrm{~s}(\Delta \tau=0.46 \Delta t)$ амплитуда индуцированного лазерным уколом скачка деформации возрастает почти до $\sim 0.8 \%$. Резкий рост амплитуды $\Delta \varepsilon_{\text {ind }}$ наблюдается в середине плато: в интервале $\Delta \tau$ от $60 \mathrm{~s}$ до $70 \mathrm{~s}(0.46-0.54 \Delta t)$ амплитуда $\Delta \varepsilon_{\text {ind }}$ возрастает скачком до $2 \%$, т. е. более чем в 2.5 раза. Затем с ростом $\Delta \tau$ скорость роста амплитуды вынужденного скачка монотонно падает и в интервале между $80 \mathrm{~s}(0.62 \Delta t)$ и $115 \mathrm{~s}(0.88 \Delta t)$ величина $\Delta \varepsilon_{\text {ind }}$ возрастает от $2.53 \%$ до $2.7 \%$, что составляет около $80 \%$ амплитуды ожидаемого 


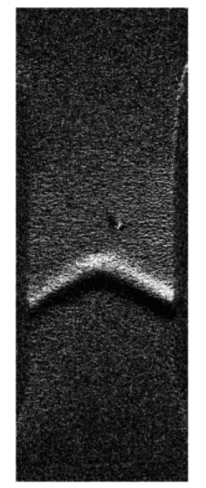

$2 \mathrm{~mm}$

30

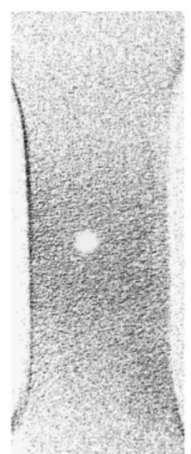

106

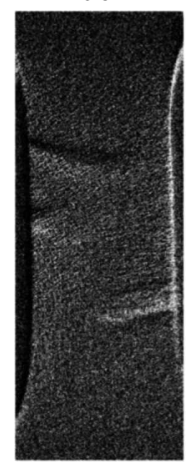

135

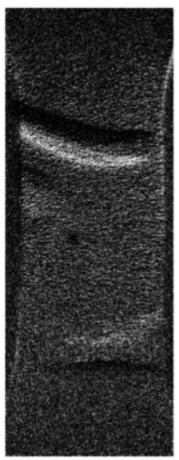

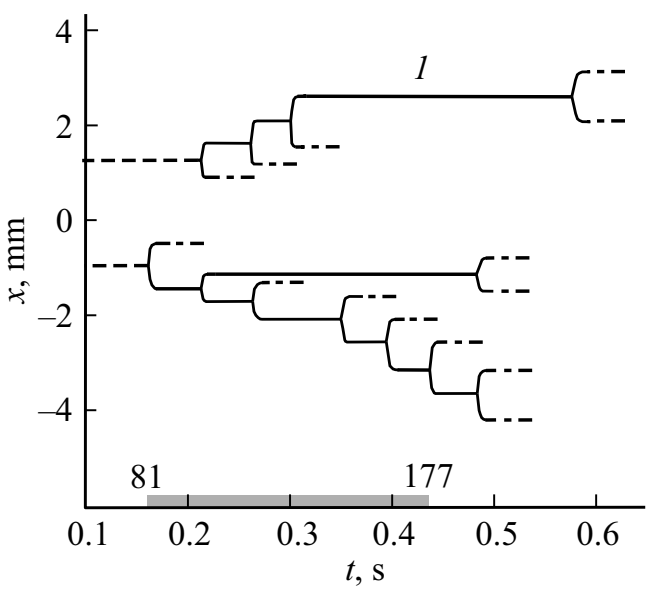

44

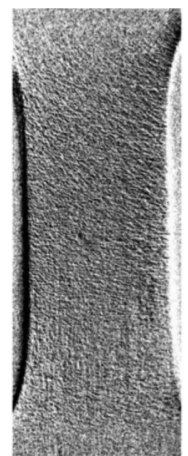

107

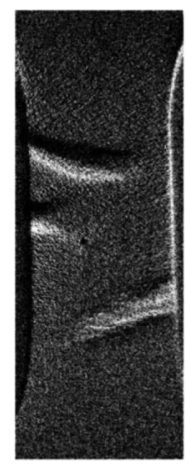

136

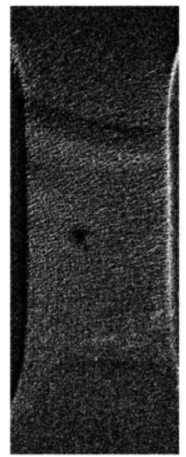

81

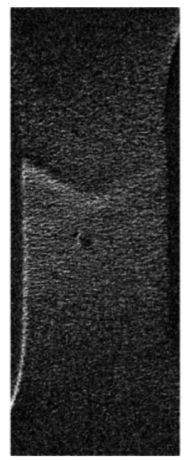

108

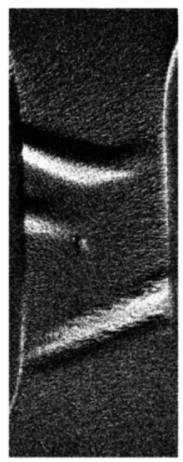

151

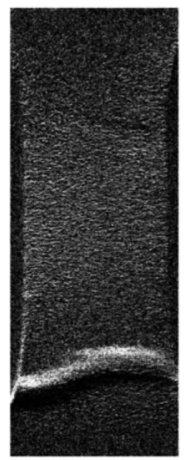

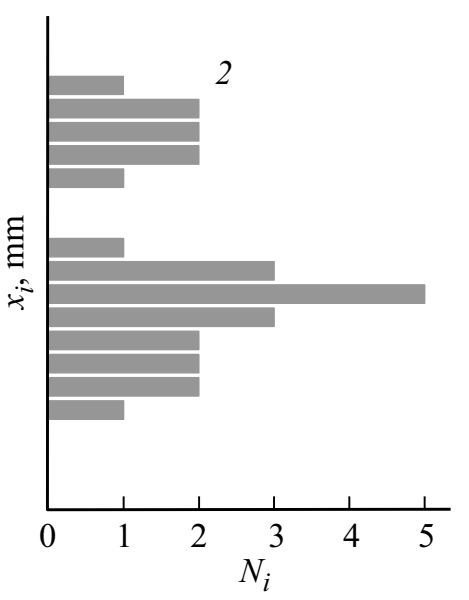

84

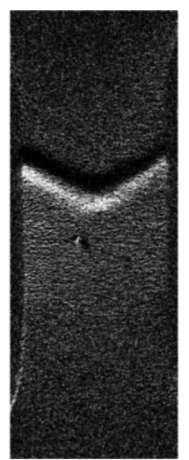

109

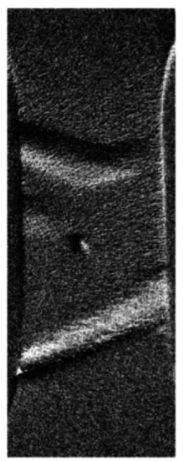

152

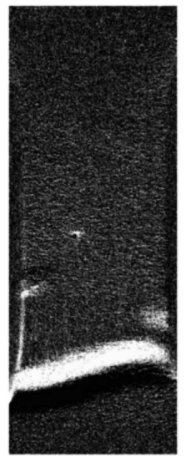

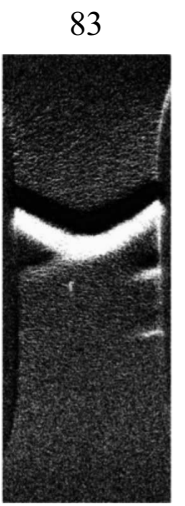

132

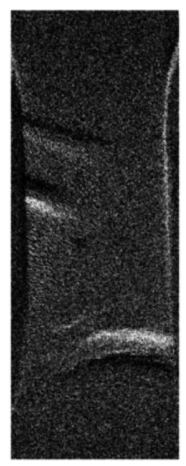

175

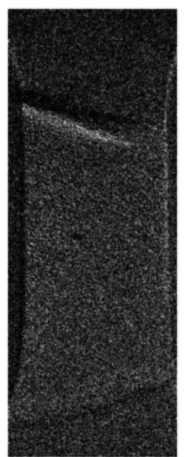

$a$

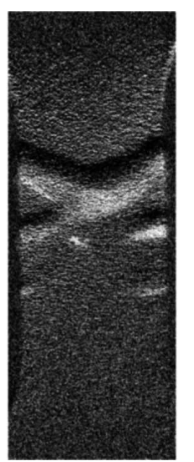

133

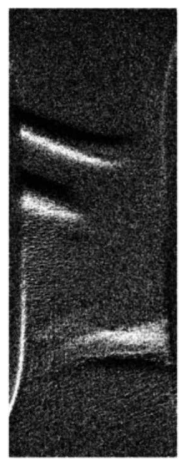

177

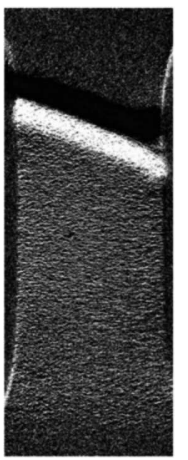

$2 \mathrm{~mm}$

Рис. 3. Результаты компьютерной обработки видеосъемки развития деформационных полос, инициированных лазерным „уколом“ поверхности сплава АМг6 в ходе растяжения со скоростью $\dot{\sigma}_{0}=0.2 \mathrm{MPa} / \mathrm{s} . P_{1}=50 \mathrm{~W}\left(\Phi_{1}=6.5 \mathrm{~kJ} / \mathrm{cm}^{2}\right), \sigma=270 \mathrm{MPa}$ : $a$ - корреляционная диаграмма (1) и пространственная гистограмма (2) деформационных полос; $b-$ фрагмент видеофильма, демонстрирующий динамику и морфологию полос. Серой полосой на оси времени отмечен временно́й интервал между кадрами 81 и 177, представленными на рис. $3, b$. 

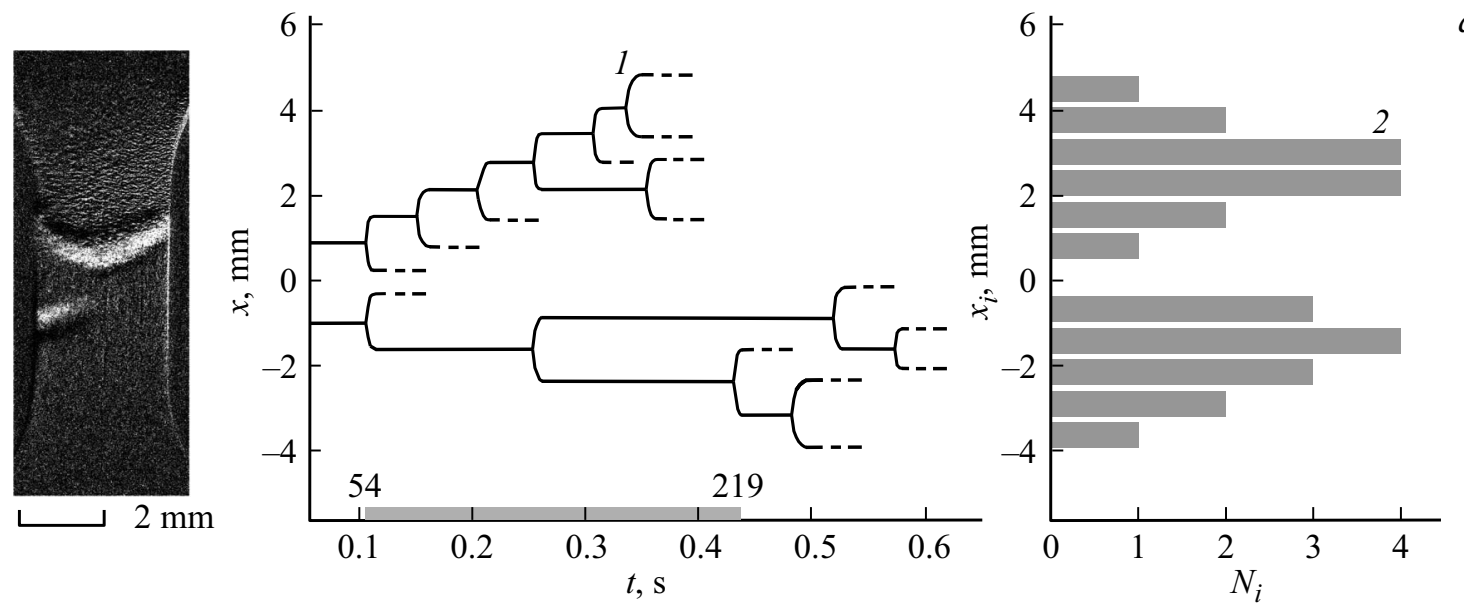

11

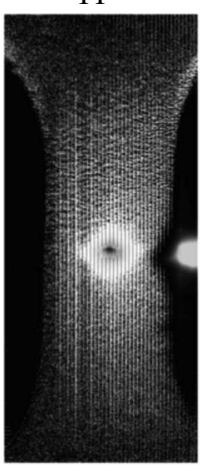

127

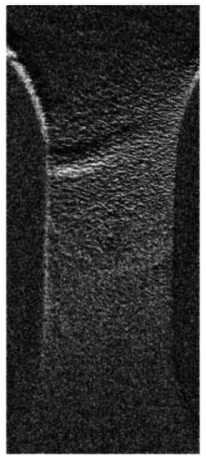

187

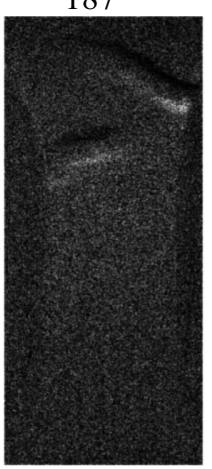

23

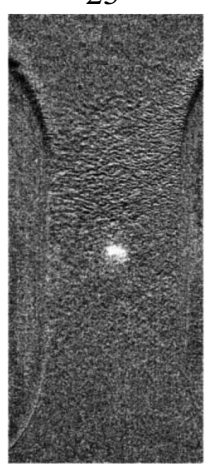

128

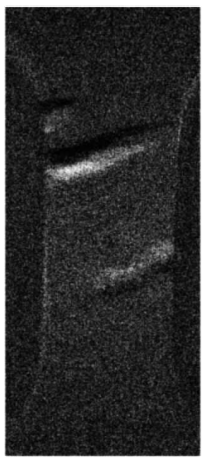

189

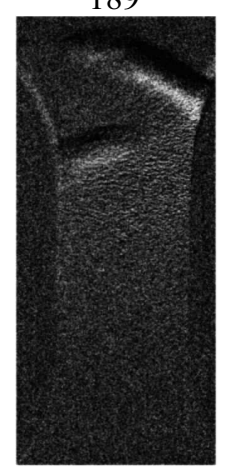

54

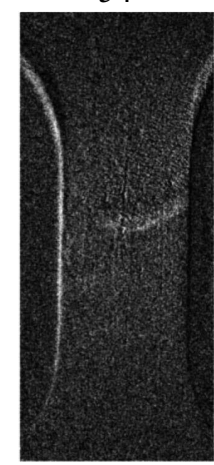

129

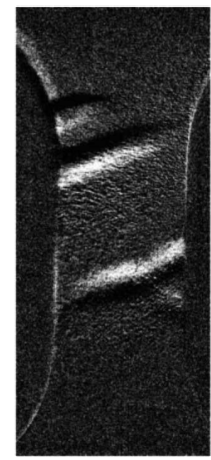

191

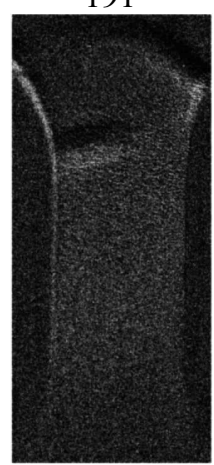

55

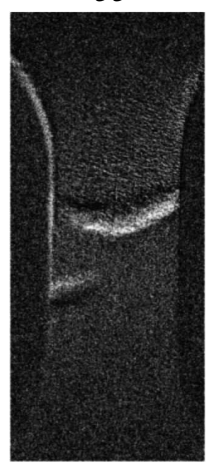

130

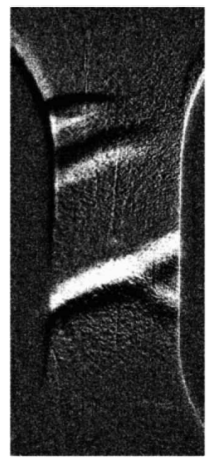

217

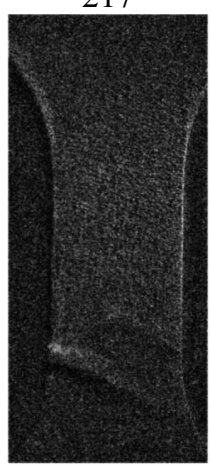

56

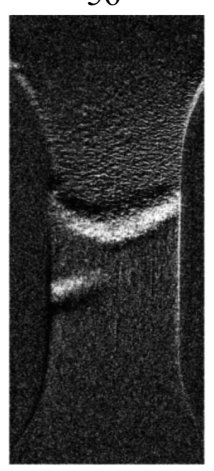

131

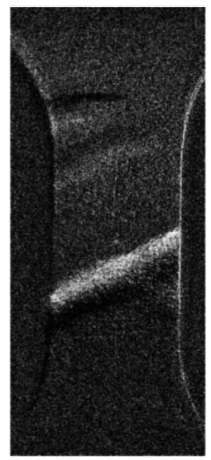

218

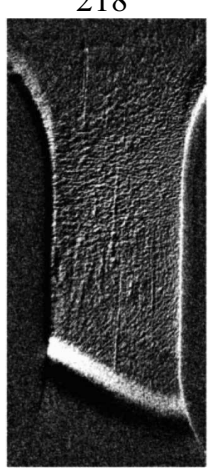

$a$

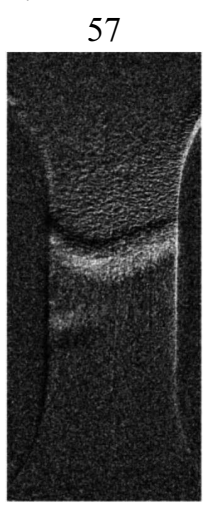

132

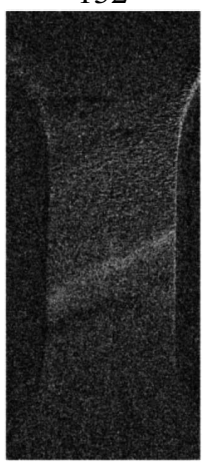

219

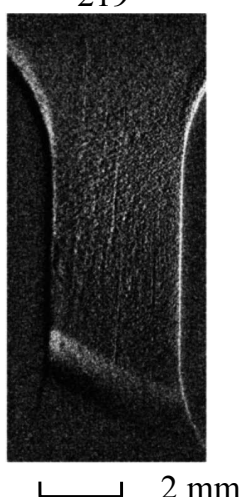

Рис. 4. То же при $P_{2}=25 \mathrm{~W}\left(\Phi_{2}=3.25 \mathrm{~kJ} / \mathrm{cm}^{2}\right)$. Серой полосой на оси времени отмечен временной интервал между кадрами 54 и 219 , представленными на рис. $4, b$. 

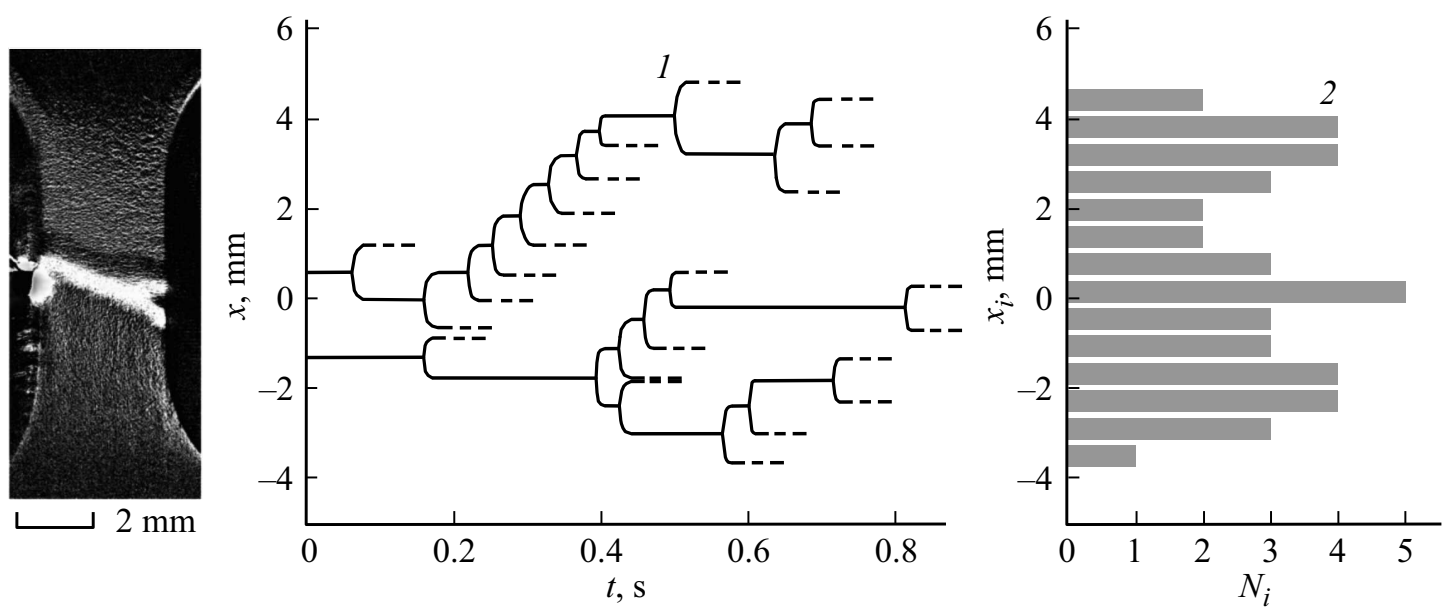

Рис. 5. Корреляционная диаграмма (1) и гистограмма (2) деформационных полос, инициированных лазерным импульсом при $P_{3}=14 \mathrm{~W}\left(\Phi_{3}=1.8 \mathrm{~kJ} / \mathrm{cm}^{2}\right)$.

в отсутствие внешних воздействий спонтанного скачка пластической деформации $\Delta \varepsilon_{\text {spont }}=3.36 \%$.

Рассмотрим теперь данные скоростной видеосъемки поверхности деформируемого образца после импульсного лазерного воздействия с плотностью потока $F_{1}=3.25 \cdot 10^{5} \mathrm{~W} / \mathrm{cm}^{2}$ при $\Delta \tau=70 \mathrm{~s}(0.54 \Delta t)$. Для анализа взаимной корреляции деформационных полос строили корреляционную диаграмму $x(t)$ - временну́ю зависимость координаты $x$ границы полосы относительно центра лазерного пятна вдоль оси растяжения образца (кривая 1 на рис. 3,a). Для исследования пространственного статистического распределения полос вдоль рабочей части образца последняя условно разделялась на 20 эквидистантных параллельных сечений, подсчитывалось количество $N_{i}$ границ полос, пересекающих каждое сечение $x=x_{i}$, и строилась гистограмма $N_{i}\left(x_{i}\right)$ (кривая 2 на рис. $3, a$ ).

Быстрая фаза формирования деформационной полосы, как известно [13], вызывает скачок разгрузки системы машина-образец, а формирование всей последовательности полос вызывает развитие скачка деформации амплитудой $\Delta \varepsilon_{\text {ind }} \approx 2 \%$ (рис. $2, b$ ). Первичная полоса зарождается на боковой поверхности плоского образца и распространяется под углом около $60^{\circ}$ к оси растяжения, т.е. в плоскости максимальных касательных напряжений (для изотропного твердого тела

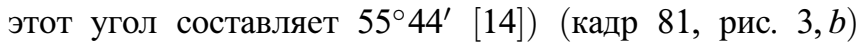
в направлении к зоне лазерного воздействия и „отражается“ в сопряженном направлении под углом около $120^{\circ}$ (кадры 82, 83). Последующие полосы зарождаются на границах предыдущих полос, как следует из корреляционной диаграммы и фрагмента видеофильма (рис. $3, b$ ) длительностью до половины развития деформационного скачка. Первичная и все последующие полосы подходят к зоне оплавления на расстояние не более $r_{1} \approx 600 \mu \mathrm{m}$; гистограмма полос имеет нулевой участок в области около $2 r_{1}$ (рис. 3, $a$, кривая 2). Такое поведение деформационных полос является следствием их „отталкивания“ от центральной цилиндрической области, упрочненной локальным лазерным воздействием.

Характерная особенность динамики и морфологии деформационных полос, представленных на типичном примере на рис. $3, b$, состоит в том, что одновременно с формированием полос, распространяющихся на фронтальной поверхности плоского образца под углом около $60^{\circ}$ (полосы 1 типа) зарождаются полосы в направлении 90 к оси растяжения (полосы 2 типа), которые распространяются под углом $60^{\circ}$ на боковой поверхности образца [7]). Примеры таких полос показаны на кадрах 83, 84 и 106-109 на рис. 3, $b$. Они стартуют от концентраторов на боковой поверхности и распространяются в сечении, близко подходящем к зоне воздействия. Такие полосы блокируются упрочненным материалом; пластическая деформация продолжается за счет зарождения и эволюции полос 1 типа.

По мере уменьшения плотности потока лазерного воздействия до $F_{2}=1.62 \cdot 10^{5} \mathrm{~W} / \mathrm{cm}^{2} \quad\left(P_{2}=25 \mathrm{~W}\right.$, $\Phi_{2}=3.25 \mathrm{~kJ} / \mathrm{cm}^{2}$ ) наблюдается следующая тенденция (см. рис. 4): полосы ближе подходят к зоне лазерного воздействия (до $r_{2} \approx 200 \mu \mathrm{m}$, нулевой участок на гистограмме соответственно уменьшается, что свидетельствует об уменьшении радиуса зоны упрочнения, уменьшается доля полос типа 2; в основном наблюдаются полосы 1 типа, которые проявляют склонность к расщеплению на сопряженные полосы (кадр 130 на рис. 4, $b$ ) и к отталкиванию от зоны воздействия (кадры 54-56), т.е. к формированию ломаной полосы с углом $\sim 120-140^{\circ}$. При плотности потока меньше $\sim 10^{5} \mathrm{~W} / \mathrm{cm}^{2}$ ломаная полоса не наблюдается. Локализация пластической деформации происходит только за счет образования полос 1 типа, которые проходят через зону термического воздействия; нулевой участок на гистограмме отсутствует и при $F_{3}<0.9 \cdot 10^{5} \mathrm{~W} / \mathrm{cm}^{2}\left(P_{3}=14 \mathrm{~W}, \Phi_{3}=1.8 \mathrm{~kJ} / \mathrm{cm}^{2}\right)$ гистограмма полос ничем не отличается от таковой в отсутствие лазерного воздействия (рис. 5). 
Таким образом, импульс лазерного излучения, воздействующий на гладкий (без скачков) участок диаграммы растяжения, вызывает зарождение и распространение деформационной полосы, которая является в свою очередь триггером развития деформационного скачка - ступени амплитудой $\Delta \varepsilon_{m} \approx 2 \%$ на диаграмме растяжения. Полоса всегда зарождается от источника на боковой поверхности поликристаллического плоского образца и первоначально распространяется в плоскости максимальных касательных напряжений. Поверхностный дислокационный источник срабатывает, видимо, в результате действия термоупругих напряжений, обусловленных достижением боковой поверхности тепловой „волны““ от очага лазерного воздействия.

Время $\Delta t_{d}$ между началом лазерного импульса (длительностью $t_{p}=20 \mathrm{~ms}$ ), вызывающего сквозное проплавление образца, и моментом срабатывания дислокационного источника полосы сильно нелинейно возрастает с ростом мощности излучения $P$ : в интервале значений $P$ от 25 до $50 \mathrm{~W} \Delta t_{d}$ растет от 100 до $120 \mathrm{~ms}$, а в интервале $12-14 \mathrm{~W} \Delta t_{d}$ не превышает $\sim 10 \mathrm{~ms}$. До тех пор, пока расплавленный металл не затвердеет после окончания лазерного воздействия, тепловой источник цилиндрической формы будет активным и создавать цилиндрическую область сжатия в объеме образца, препятствуя распространению деформационной полосы. Согласно [15], остывание цилиндра происходит по закону $T \sim \sum_{n} \mu_{n}^{-2} \exp \left(-\mu_{n}^{2} F_{0}\right)$. Этот ряд быстро сходится, так что постоянную времени остывания можно оценить как $\tau_{T} \approx l_{d}^{2} / a \mu_{1}^{2}$. (Здесь $l_{d}$ имеет смысл расстояния между осью цилиндрического канала и дислокационным источником на боковой поверхности цилиндра, $F_{0}=a t / l_{d}-$ критерий Фурье, а первый коэффициент разложения $\mu_{1}=2.4048$ [15]). Учитывая, что по данным видеосъемки $l_{d} \approx 1.8 \mathrm{~mm}$, получим оценку $\tau_{T} \approx 13 \mathrm{~ms}$. Эта оценка совпадает по порядку величины с временем задержки срабатывания дислокационного источника в отсутствие сквозного проплавления.

Отметим, что во многих поликристаллических металлах и сплавах наблюдается зона структурного упрочнения после действия лазерного импульса [16]. Пробивание лазерным импульсом сквозного отверстия в исследуемых образцах сплава АМг6 происходит, как обнаружено, при плотности потока излучения выше $10^{5} \mathrm{~W} / \mathrm{cm}^{2}$ $(P>14 \mathrm{~W})$. После лазерного воздействия измеряли микротвердость HV на противоположной относительно кратера поверхности плоского образца. Затем строили радиальную зависимость микротвердости для образцов, подвергнутых лазерному импульсному воздействию с плотностью энергии $\Phi_{1}=6.5 \mathrm{~kJ} / \mathrm{cm}^{2}, \Phi_{2}=3.24 \mathrm{~kJ} / \mathrm{cm}^{2}$ и $\Phi_{3}=1.8 \mathrm{~kJ} / \mathrm{cm}^{2} \quad\left(P_{1}=50 \mathrm{~W}, P_{2}=25 \mathrm{~W}\right.$ и $P_{3}=14 \mathrm{~W}$ соответственно). В последнем случае $\left(P_{3}=14 \mathrm{~W}\right)$ заметных изменений микротвердости не обнаружено. Распределения значения $\mathrm{HV}$ демонстрируют эффект упрочнения при плотности энергии излучения $\Phi_{1}$ и $\Phi_{2}$ (рис. 6).
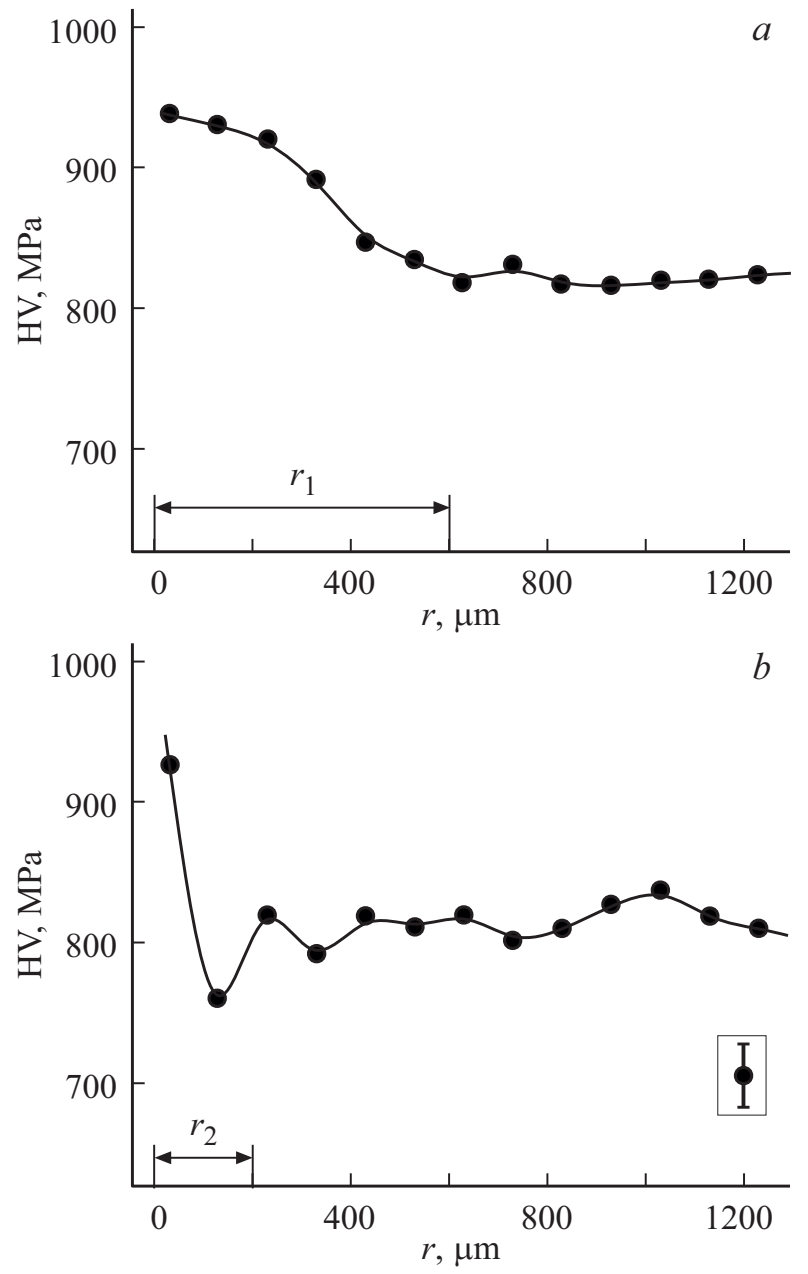

Рис. 6. Распределение микротвердости HV вдоль радиуса $r$ от края отверстия, полученного в результате воздействия импульса лазерного излучения: $a-\Phi_{1}=6.5 \mathrm{~kJ} / \mathrm{cm}^{2}$, $b-\Phi_{2}=3.25 \mathrm{~kJ} / \mathrm{cm}^{2}$. На вставке - погрешность измерения микротвердости, усредненная по десяти измерениям; $r_{1} \approx 600 \mu \mathrm{m}$ и $r_{2} \approx 200 \mu \mathrm{m}$ - радиусы зон „отталкивания“ деформационных полос при плотности энергии $\Phi_{1}$ и $\Phi_{2}$ соответственно

Максимальная микротвердость вблизи края отверстия, как видно из рисунка, достигает величины около $950 \mathrm{MPa}$, что почти на $100 \mathrm{MPa} \mathrm{превышает} \mathrm{исходное} \mathrm{зна-}$ чение микротвердости (вдали от зоны лазерного воздействия). При плотности энергии, равной $\Phi_{2}=3.24 \mathrm{~kJ} / \mathrm{cm}^{2}$ микротвердость демонстрирует чередование зон упрочнения и разупрочнения: за ближней к зоне оплавления упрочненной областью следует зона разупрочнения, значение микротвердости падает до $760 \mathrm{MPa}$, затем следует локальное упрочнение до $820 \mathrm{MPa} \mathrm{на} \mathrm{расстоянии} \mathrm{около}$ $200 \mu \mathrm{m}$, которое оказывается непреодолимым для деформационной полосы. Радиусы зон упрочнения, около 600 и $200 \mu \mathrm{m}$, при плотностях энергии $\Phi_{1}$ и $\Phi_{2}$ (рис. $6, a, b$ ) совпадают с данными видеосъемки с соответствующими радиусами „отталкивания“ полос деформации $r_{1}$ и $r_{2}$ (рис. $3, b$ и $4, b$ ). Поэтому можно заключить, что 
причиной отталкивания деформационных полос от зоны воздействия лазерного импульса является структурное упрочнение материала, обусловленное генерацией дефектов решетки термическими напряжениями, превышающими динамический предел текучести. При плотности потока $F \leq 10^{5} \mathrm{~W} / \mathrm{cm}^{2}$ сквозное проплавление образца не происходит; на внешней поверхности образуется кратер со следами оплавления, который однако также провоцирует образование полос в деформируемом образце. И наконец, при $F \leq 10^{4} \mathrm{~W} / \mathrm{cm}^{2}$ лазерный импульс не оказывает заметного влияния на полосообразование и прерывистую деформацию сплава АМг6.

Таким образом, деформационный отклик на локальное воздействие лазерного луча сильно нелинейно зависит от временно́й фазы воздействия. Если момент импульсного воздействия приходится на начальный участок плато, то это не вызывает заметного скачка деформации, а если на последнюю треть плато - то то же самое воздействие (лазерный укол) провоцируют макроскопический скачок деформации. Таким образом, по мере приближения к ожидаемой „катастрофе“ - спонтанному развитию макроскопического скачка деформации с амплитудой в несколько процентов - материал становится все более неустойчивым, а мерой этой неустойчивости является амплитуда вынужденного скачка, спровоцированного внешним локальным воздействием.

Следует отметить, что в последнее время в литературе появился термин „сейсмология“ пластической деформации на основании аналогии между статистическим распределением амплитуд импульсов акустической эмиссии или скачков напряжения при развитии дислокационных лавин и статистическим распределением магнитуд сейсмических событий при землетрясениях $[17,18]$. Макроскопические скачки деформации можно рассматривать как своего рода „землетрясения“ образца (термин, который ввел Андраде в 1910 году, описывая прерывистую ползучесть медных образцов [19]). Подобно землетрясениям они происходят, видимо, в результате спонтанной релаксации внутренних напряжений, которые медленно накапливаются в материале на плато между скачками, а внешнее локальное воздействие выступает здесь лишь как триггер - спусковой крючок для быстрой релаксации внутренних напряжений. Поэтому деформационный отклик на внешнее локальное воздействие сильно нелинейно зависит от времени накопления внутренних напряжений, поскольку землетрясения и скачкообразная деформация металлов характеризуются сильно нелинейной пороговой динамикой.

\section{4. Заключение}

Локальное воздействие лазерного импульса ИК-излучения длительностью $20 \mathrm{~ms}$, и плотностью потока $>10^{5} \mathrm{~W} / \mathrm{cm}^{2}$, вызывающее сквозное проплавление плоского образца, провоцирует зарождение полосы деформации и последующее развитие макроскопического, ам- плитудой несколько процентов скачка деформации продолжительностью более $500 \mathrm{~ms}$. Следовательно, нагрев локальной области образца импульсным лазерным излучением является лишь триггером деформационного скачка, который затем развивается за счет релаксации внутренних напряжений, накопленных в материале на гладком участке кривой растяжения.

Результаты настоящей работы направлены на решение малоизученной проблемы термопрочности и термопластичности металлических сплавов, демонстрирующих прерывистую деформацию (эффект Портевена-Ле Шателье, эффект Савара-Массона, прерывистую ползучесть), которые находятся одновременно под действием механических и локальных термических нагрузок. Эта проблема существенно отличается от проблемы термопрочности хрупких материалов [20] и оптической прочности лазерной оптики $[21,22]$ ключевой ролью деформационных полос, вызывающих развитие макропластических неустойчивостей и, в конечном счете, разрушение материала. Практически эта проблема связана с оценкой рисков развития макролокализованной пластической деформации и последующего развития трещин при пробивании сквозных отверстий диаметром на порядок меньше толщины листового материала в зонах концентрации напряжений (вблизи сварных соединений, геометрических концентраторов и т.д.). Необходимы дальнейшие исследования обнаруженного влияния локального лазерного излучения на пластическую неустойчивость металлических сплавов, демонстрирующих прерывистую деформацию, для учета этого явления в технологиях лазерной сварки, прецизионной резки металла, пробивания отверстий, маркировки поверхности и т.д.

\section{Список литературы}

[1] Дж.Ф. Белл. Экспериментальные основы механики деформируемых твердых тел. Наука, М. (1984). Ч. 2. 432 с.

[2] A. Yilmaz. Sci. Technol. Adv. Mater. 12, 063001 (2011).

[3] А.А. Шибков, А.Е. Золотов. Письма в ЖЭТФ 90, 412 (2009).

[4] А.А. Шибков, А.Е. Золотов, М.А. Желтов, А.А. Денисов, М.Ф. Гасанов. ЖТФ 84, 40 (2014).

[5] Y. Estrin, L.P. Kubin. Continuum models for materials with microstructure / Ed. H.-B. Muhlhaus. Wiley \& Sons, N.Y. (1995). P. 395.

[6] A.A. Shibkov, A.A. Denisov, M.A. Zheltov, A.E. Zolotov, M.F. Gasanov. Mater. Sci. Eng. A 610, 338 (2014).

[7] А.А. Шибков, А.А. Денисов, А.Е. Золотов, С.С. Кочегаров. ФTT 59, 96 (2017).

[8] А.А. Шибков, А.Е. Золотов, М.А. Желтов, А.В. Шуклинов, А.А. Денисов, С.С. Кочегаров. Коррозия: материалы, защита 8, 19 (2017).

[9] А.А. Шибков, М.А. Желтов, М.А. Лебедкин, В.В. Скворцов, Р.Ю. Кольцов, А.В. Шуклинов. Заводская лаборатория 71, 20 (2005).

[10] Дж. Рэди. Действие мощного лазерного излучения. Мир, М. (1974). 469 c. 
[11] В.М. Белецкий, Г.А. Кривов. Алюминиевые сплавы. КОМИНТЕХ. 12. (2005). 365 c.

[12] А.А. Шибков, М.А. Желтов, М.Ф. Гасанов, А.Е. Золотов. ФTT 53, 1873 (2011).

[13] A.A. Shibkov, M.F. Gasanov, M.A. Zheltov, A.E. Zolotov, V.I. Ivolgin. Int. J. Plast. 86, 37 (2016).

[14] Р. Хилл. Математическая теория пластичности. Гостехиздат, М. 408 (1956).

[15] А.В. Лыков. Теория теплопроводности. Высш. шк., М. 600 (1967).

[16] Л.И. Миркин. Физические основы обработки материалов лучами лазера. МГУ, М. (1975). 384 с.

[17] J. Weiss, F. Lahaie, J.-R. Grasso. J. Geophys. Res. 105, 433 (2000).

[18] M.C. Miguel, A. Vesplignanl, S. Zapperi, J. Weiss, J.-R. Grasso. Nature 410, 667 (2001).

[19] E.N. da C. Andrade. Proc. Roy. Soc. 84, 1 (1910).

[20] А.Г. Ланин, И.И. Федик. Термопрочность материалов. Подольск, НИИ НПО „Луч“ (2005). 312 с.

[21] А.А. Маненков, А.М. Прохоров. УФН 148, 179 (1986).

[22] Ю.И. Головин, А.В. Горбунов, А.А. Шибков. ФТТ 30, 1931 (1988).

Редактор Т.Н. Василевская 